\title{
Editorial
}

\section{Ageing, longevity and fitness: towards new paradigms in healthy ageing}

\author{
Nugroho Abikusno \\ Department of Nutrition, Faculty of Medicine, Trisakti University
}

We have nearly reached the end of the second decade of the Millennium. Within 5 years we hope the Third Ageing Summit will be held to discuss lessons learned and future directions in the field of ageing and longevity. I mention the word longevity since many countries especially in the Asia Pacific region, the second Hub of Ageing after the Western world countries, have experienced this phenomenon since the early years of this Millennium. ${ }^{(1)}$

Looking back at the previous two Ageing summits, the first was held in the early eighties in Vienna and had nursing homes as the main paradigm in solving the issues related to an ageing population mostly in the post-industrial Western world. Two decades later the second Ageing summit was held in Madrid well known for the declaration of Madrid International Plan of Action on Ageing (MIPAA) endorsed by 57 countries in the world. ${ }^{(2)}$ This declaration in a nutshell consisted of 3 pillars to solving the issues of ageing namely 1) participation of older persons in development, 2) provision of quality social and health services for the elderly, and 3) creating an age-friendly environment that would support a society for all ages and in the case of the elderly the right to age in a place which would provide a supporting environment for them.

Meanwhile at the global level most of the countries in the world were battling poverty in all forms and hence the millennium development goals (MDGs) was the overall direction taken by all countries in the world. This was followed by the present sustainable development goals (SDGs) where issues of poverty eradication remained the ultimate goal especially focused on women, children and elderly. Besides the issue of poverty in the elderly, this vulnerable group is mostly affected not only by famine but also natural disasters as frequently experienced by countries due to earthquakes and most recently tsunamis such as the great Asian tsunami in 2004.

Indonesia, as an example of an ageing society in the Asia Pacific region, has entered its demographic bonus phase 1 period. This is an ideal period for it to develop infrastructure and age-friendly human resources at all tiers that provide services for the older population as well as those disabled so that they become not a burden but an asset in development as espoused by the 3 pillars of MIPAA. The second phase of the demographic bonus which follows will be around the $100^{\text {th }}$ anniversary of Indonesia where the development process will reach the first cycle of its national development as the largest island archipelago nation-state in the world. At that moment the older population will be around 25 percent of its total population. The total number of older people will be around 50 million and the age dependency ratio will be around 25 where 1 older person is supported by only 4 young people. The age dependency ratio is around 12 presently so 1 older person is still supported by 10 young people who are mainly family members. In the future the burden of young people to support their elders, specifically caregiving services will increase because 1) there are not many young people available, 2) the present baby boomers are 
entering the last phase of their lives where life expectancy at 60 years is around 20 years but the healthy life expectancy is only around 15 years; meaning the last years of their lives will be mostly at home and bedridden, and 3) the next batch of baby boomers have entered their own pension age (the 3-generations in one roof concept).

The main issue in this situation is how do we attempt to extend their healthy life expectancy by shortening the period where they are living at home and bedridden. Presently, population-wise as related to Healthy ageing concept starts from the very beginning of one's life known as the life course approach. Every stage of vulnerability prevention such as detection of anemia in female adolescents is followed by other specific program interventions in the stages of pregnancy, infancy, childhood, adulthood and lastly old age. In 2012, this concept has been espoused at the International Conference on Healthy Ageing held in Kuala Lumpur and at the World Health Organization/South-East Asia Regional Office region the Regional strategy for healthy ageing 2013-2018 became a major guidance for all thirteen of its member nations. ${ }^{(3)}$

In ageing we are aware of our chronological age as measured by our birth certificate and the date of birth in our identity card or passport. The biological age is observed by signs of ageing such as white or gray hair, coarse skin, being over or undernourished or suffering from various noncommunicable diseases such as hypertension, diabetes, hypercholesterolemia, to name a few. All these signs and many more will affect our physical appearance as an image of being older than one's actual age. What is more important and often overlooked is one's fitness age. Assessment of fitness status can apply the following measures such as maximal oxygen volume, waist circumference, duration of exercise or even grip strength. ${ }^{(4)}$

These measurements are important when we deal with fitness in the elderly together with nutrition. ${ }^{(5)}$ Since most of the elderly will follow 2 distinct prototypes, namely obesity mostly in women or frailty mostly in men above 70 years. What is more distressing is the underlying disorder suffered by the elderly in this condition namely sarcopenia of their muscle cells which are less in number as well as size eventually leading to the general condition of frailty and signs of old age. Geriatric syndromes can be in the form of incontinence, insomnia, delirium (or confusion) eventually followed (if undetected) by dementia, falls, osteoporosis and weight loss.

Thus, in this situation the life course approach will be the paradigm of ageing in the future. ${ }^{(6)}$ Healthy life style behavior should begin at the earliest life stage as possible and it is never too late to start this type of lifestyle. It consists of eating a healthy balanced diet, routine simple exercise such as walking, running, bicycling or swimming, meditation or daily deep breathing exercise, sufficient sleep especially between 10 pm to $3 \mathrm{am}$, brain exercise such as reading, comprehension, writing and discussion or learning new languages, and last but not least social interaction among family, friends, neighbors and/ or colleagues.

\section{REFERENCES}

1. United Nations. World population report 2015. New York.

2. United Nations. The Madrid international plan of action on ageing and the political declaration. New York: United Nations;2002.

3. World Health Organization/South-East Asia Regional Office. Regional strategy for healthy ageing. Delhi: World Health Organization, Regional Office for South-East Asia;2014.

4. Roberts HC, Denison HI, Martin HI, et al. A review of measurement of grip strength in clinical and epidemiological studies: towards a standardized approach. Age Ageing 2011; 40: 423-9. doi: 10.1093/ageing/afr051.

5. Trouwborst I, Verreijen A, Memelink R. Exercise and nutrition strategies to counteract sarcopenic obesity. Nutrients 2018;10:605. doi: 10.3396/nu/ 10050605.

6. Kuruvilla S, Sadana R, Montesinos EV, et al. A life-course approach to health: synergy with sustainable development goals. Bull WHO 2018;96:42-50. doi: http://dx.doi.org/10.2471/ BLT.17.198358. 